\title{
Food items consumed by students attending schools in different socioeconomic areas in Cape Town, South Africa
}

\author{
Norman J. Temple, Ph.D. ${ }^{\mathrm{a}, *}$, Nelia P. Steyn, M.P.H., Ph.D. ${ }^{\mathrm{b}}$, \\ Neil G. Myburgh, B.Ch.D., M.Ch.D. ${ }^{c}$, and Johanna H. Nel, D.Sc. ${ }^{\mathrm{d}}$ \\ ${ }^{a}$ Centre for Science, Athabasca University, Athabasca, Alberta, Canada \\ ${ }^{\mathrm{b}}$ Chronic Diseases of Lifestyle Unit, Medical Research Council, Cape Town, South Africa \\ ${ }^{\mathrm{c}}$ Centre for Oral Health, University of the Western Cape, Cape Town, South Africa \\ ${ }^{\mathrm{d}}$ Department of Logistics, Stellenbosch University, Stellenbosch, South Africa
}

Manuscript received February 19, 2005; accepted July 17, 2005.

\begin{abstract}
Objective: We investigated the food consumption patterns of adolescent students at schools. Our findings are intended to reveal the overall nutritional quality of foods eaten by students at school, including foods brought to school and foods purchased at school.

Methods: A questionnaire was completed by 476 students, mostly from grades 7 and 10, from 14 schools in Cape Town, South Africa. The schools were representative of the various ethnic groups and socioeconomic strata of the population. The questionnaire requested information on eating habits at school, foods brought to school and food purchases, and breakfast consumption before school. We also tested whether students knew which foods are healthy and which are less healthy choices.

Results: The students were mostly 12 to $16 \mathrm{y}$ of age (mean age $14.5 \mathrm{y}$ ). The large majority had breakfast before school $(77.8 \%)$ and ate at school (79.7\%). Food was brought to school by $41 \%$ to $56 \%$, whereas $69.3 \%$ purchased food at school, mainly at the school store (tuck shop). Predefined "unhealthy" foods brought to school outnumbered "healthy" ones by 2 to 1 . Among students who purchased food at school, $70.0 \%$ purchased no healthy items, whereas $73.2 \%$ purchased two or more unhealthy items. With six foods $84 \%$ of students correctly stated whether they were healthy or unhealthy; however, with cola drinks, samoosas (deep-fried pastry with spicy filling), and pies, only $47 \%$ to $61 \%$ knew that these were less healthy choices. Students' scores on this question were unrelated to whether they purchased healthy or unhealthy foods. Students who attended schools of high socioeconomic status were twice as likely to bring food to school $(64.7 \%$ versus $31.0 \%, P<$ $0.001)$, scored higher marks on the quiz of healthy versus unhealthy foods $(P<0.01)$, but were no more likely to purchase healthy food.

Conclusions: The large majority of food eaten by adolescent students in Cape Town is classified as being unhealthy choices. This applies to foods brought to school and food purchases. Consideration needs to be given to policy measures to improve this situation and to improve education of students and their parents. (C) 2006 Elsevier Inc. All rights reserved.
\end{abstract}

\section{Introduction}

The dietary pattern that predisposes to obesity, type 2 diabetes, hypertension, coronary heart disease, and other

This work was funded by Athabasca University, Canada.

* Corresponding author. Tel.: +780-469-3982; fax: +780-675-6186.

E-mail address: normant@athabascau.ca (N.J. Temple). chronic diseases of lifestyle starts in childhood [1-4]. Reports from different countries with low and high incomes have shown that many children habitually consume a nutritionally poor diet [5-8]. Children obtain their food from several sources, one of which is shops at schools. Despite the potential effect of that source of food on the overall nutritional quality of the diets of children, very little study has been made of this, particularly in developing countries. 
One American study reported that almost $90 \%$ of foods sold in school stores are high in fat and/or sugar [9], which led us to speculate about more disadvantaged communities such as those found in Africa.

Little is known concerning the sale of food in schools in South Africa. A literature search yielded only two studies. One was an evaluation of food items consumed by 289 Pedi students in a poor rural area of Limpopo Province in the north of South Africa [10]. In this study, undertaken in 1992 , it was found that only $10 \%$ of students took lunch to school, whereas $22 \%$ regularly bought snacks at the school store (called a "tuck shop" in South Africa). A more recent study was undertaken at a private school in Cape Town, mainly because of concerns by the school principal about the overall dietary habits of the students and the fact that $10 \%$ of them were obese [11]. This study noted that a large proportion of students buy food items at school, most of which comprise energy-dense items that are high in fat and sugars, typically called "junk food" or "fast food" in South Africa and North America.

The widespread availability of junk foods such as candy, potato chips (crisps), and soft drinks may have a negative effect on the nutritional quality of the diet. The key features of such foods are the large content of fat and/or sugar, high caloric values, and the relatively low content of vitamins, minerals, and dietary fiber. Data from a large study of American children and adolescents ages 8 to $18 \mathrm{y}$ associated consumption of foods of low nutrient density with increased energy intake but decreased intake of several micronutrients [12]. Similarly, another American study of subjects in this age group associated consumption of these foods with higher energy and fat intakes but lower intakes of dietary fiber, fruit, and non-starchy vegetables [13]. One particular problem is the consumption of soft drinks such as cola. In North America sales of these drinks have grown rapidly over the past $20 \mathrm{y}$. Because these drinks tend to displace more nutritious beverages such as milk, this trend has had a negative effect on the overall nutritional quality of the diet of children $[14,15]$. Consistent with this trend, junk foods are associated with the rising tide of obesity $[16,17]$.

In 1999, the first National Food Consumption Survey was undertaken in 1- to 9-y-old children in South Africa [18]. One objective was to determine the degree of malnutrition in a representative sample of the pediatric population. Nationally, the prevalence of stunting (height for age $<$ minus 2 standard deviations [19]) was $19.3 \%$, being highest in the 1- to 3-y-old children (24\%) and in children of farm workers $(26 \%)$. The prevalence of combined overweight and obesity (body mass index $\geq 25 \mathrm{~kg} / \mathrm{m}^{2}$ ) was $17.2 \%$ at the national level, nearly as high as the figure for stunting [20]. Hence, South Africa can currently be regarded as a country in transition with regard to having under- and overnutrition in the population. With this in mind, the issue of foods sold at schools obviously may contribute to these conditions.

This study had four aims. First, to record the food consumption patterns of students at school, including foods brought to school and purchases from stores in schools and from nearby commercial outlets (vendors). Second, we investigated whether differences in socioeconomic status (SES) were related to students' buying and consumption patterns. Third, we examined breakfast habits of the participants. Fourth, we assessed their knowledge with regard to which foods were healthy. The findings should indicate the overall nutritional quality of foods eaten by students at school and the nutritional significance of their food purchases.

\section{Materials and methods}

\section{Study area and population}

The study was carried out in Cape Town, a city of great contrasts. Due to its political history, Cape Town has been divided into different areas and suburbs where traditionally white, colored (mixed ancestry), and black South Africans lived in separate areas by law. By virtue of the restrictions on the groups of color, the SES of black and colored people was generally far lower than that of most whites [21]. Hence, in South Africa, SES is frequently regarded as a proxy for race. Since 1994 and democratization, most of these physical areas have remained largely unchanged, although there has been some movement from the lower SES areas to the higher ones.

The study area of metropolitan Cape Town was first stratified into these traditional ethnic areas and their SESs. These were confirmed by rates and taxes paid in the different areas. The schools were then drawn randomly and proportionally from each SES. Of 14 schools, four were from traditionally black areas, five were from colored areas, one was from a heterogeneous area, and four were from traditionally white residential areas. None of the schools was found to participate in an organized, subsidized feeding scheme because such schemes are mainly to be found at primary schools in lower grades. A total of 476 students, mostly from grades 7 and 10 , agreed to complete a questionnaire that requested information on their eating habits. Not all grades were catered for at all schools. Those classes in grades 7 and 10 that were available participated in the study. No students with mental disabilities were included in the sample.

\section{Questionnaire and school visits}

We designed a self-completion, three-page questionnaire that elicited information about (1) whether breakfast was consumed, (2) whether food was brought to school and what items were brought, and (3) whether foods were purchased at school and what foods were purchased. The questionnaire was an adaptation of a questionnaire that was used in a previous study that was undertaken in black children who resided in rural areas of Limpopo Province [10] and that was later used at a private school in Cape Town [11]. 
Students were also required to classify several foods as being healthy or unhealthy. For the purpose of this study, foods were considered to be unhealthy if they have most of the following characteristics: high in fat, added sugar, and sodium, low in fiber, and a low nutrient density. Conversely, foods considered to be healthy were those with the opposite features: low in fat, added sugar, and sodium, high in fiber, and a high nutrient density. Questions focused on the students' actions on the previous day (or previous Friday if the questionnaire was completed on a Monday) in a manner similar to that of a $24-\mathrm{h}$ dietary recall. The questionnaire is available from the lead author.

The questionnaires were administered in August and September 2003 by senior health professional students, including dentistry, nursing, and dietetics, from the University of the Western Cape. They first attended a training session given by the principal investigators. The students were randomized into five teams, each with about five members. Each team first visited a pilot school that was not included in the sample to ensure that the questionnaire was suitable for use in Cape Town. This resulted in some modifications to the questionnaire. Each team then visited two to four schools in the sampled areas.

\section{Ethics}

A research proposal was submitted to the Department of Education in the Western Cape Province for approval. The department provided a list of all the schools in metropolitan Cape Town. Their conditions for ethical approval were that the headmaster of each school gives consent, that students be clearly informed about the study, that participation be optional and anonymous, and that written consent be obtained from each participant. All these conditions were complied with. In addition, approval for the study was given by the research ethics boards of Athabasca University and the University of the Western Cape.

\section{Data analysis}

Data were entered onto Excel (Microsoft, Redmond, WA, USA) spreadsheets and then analyzed with SPSS statistical software (SPSS, Inc., Chicago, IL, USA). Descriptive statistics were calculated first, with the purpose of looking for outliers and addressing other potential data quality issues.

Chi-square tests were used for analyses involving categorical data, and $t$ tests were calculated for comparisons of means of continuous variables across groups as defined by binary variables such as gender. In cases where it was thought that the assumptions for a $t$ test might be violated (such as a student's grade), non-parametric Mann-Whitney $\mathrm{U}$ test was used. For testing relations between pairs of continuous variables, Pearson's correlation coefficients were calculated. $P=0.05$ was considered statistically significant.

\section{Results}

The sample consisted of 476 students, and $57.1 \%$ were girls. Their age was $14.5 \pm 2.0$ y (mean \pm standard deviation; age range 11-21 y). The large majority (84.5\%) was 12 to $17 \mathrm{y}$ of age. Subjects were mostly in grades 7 and 10 , with $51.5 \%$ in grade 7 and $34.5 \%$ in grade 10 .

We examined the data for internal consistency. This was done by comparing answers with questions in which, for example, if the student answered "yes" to question X, then, to be consistent, they should also have answered "yes" to question Y. With five pairs of questions, we observed that the proportion of answers that were contradictory were approximately $5 \%$ to $10 \%$. However, with two pairs of questions, about $22 \%$ of the answers were contradictory. The latter cases are best explained by students misunderstanding a question. Overall, this indicates that the degree of internal consistency was reasonably good, especially considering the age of the subjects.

The large majority of students had breakfast before school $(77.8 \%)$ and ate at school (79.7\%). A smaller proportion actually brought food to school. Unfortunately, the results for this question were not consistent. When students were asked, "Did you bring food to school yesterday?" 40.7\% answered "yes." However, when asked to state the foods they brought to school, $55.5 \%$ indicated at least one food. Our conclusion to this dilemma is that the answer lies between $41 \%$ and $56 \%$.

We recorded the type of food that students brought to school (Table 1). Unhealthy foods outnumbered healthy ones by a ratio of a ratio of $2: 1$. White bread was brought by $25.4 \%$ and only $10.5 \%$ had brown bread. Although candy and potato chips (crisps) were brought by $25.0 \%$ and $23.9 \%$, respectively, fruit was brought by $16.8 \%$.

The data indicated that $69.3 \%$ of students had purchased food at school on the previous day. This food was purchased mainly at the school store: of those students who purchased food at school, $72.9 \%$ purchased it at the store, $20.4 \%$

Table 1

Food brought to school by students

\begin{tabular}{lll}
\hline $\begin{array}{l}\text { Food } \\
\text { classification }\end{array}$ & Food & $\begin{array}{l}\text { Proportion (\%) of } \\
\text { students bringing } \\
\text { this food* }\end{array}$ \\
\hline Healthy & Spread on bread or crackers & 21.4 \\
& Fruit & 16.8 \\
& Meat, processed meat, fish, eggs & 13.0 \\
& Brown bread & 10.5 \\
& Fruit juice & 9.2 \\
& Milk and milk products & 9.0 \\
Unhealthy & White bread & 25.4 \\
& Candies (sweets), chocolates & 25.0 \\
& Potato chips (crisps) & 23.9 \\
& Soft drinks (high sugar content) & 15.8 \\
& French fries (fried chips) & 12.2 \\
& Cookies (biscuits), cakes, and similar & 10.7
\end{tabular}

* Only those food items brought by at least $9 \%$ of students are listed. 
bought it from a local vendor, and 6.8\% bought foods from both outlets. The amount of money spent by those students who actually purchased food was $5.4 \pm 8.7$ rands (mean \pm standard deviation). This is equivalent to about $\$ 0.75$.

We examined factors that might be associated with whether students purchased food at school. There was no association with the age of the students or whether they had eaten breakfast. However, buying food was more common among girls $(74.6 \%$ versus $62.9 \%, P<0.01)$ and those students who did not bring food to school $(75.3 \%$ versus $60.7 \%, P<0.01$ ).

Table 2 lists the foods most commonly purchased by students at school. The substantial majority of food purchases was unhealthy, being dominated by candies, chocolates, soft drinks (usually with a high content of sugar), French fries, and potato chips. Among students who purchased food at school, $70.0 \%$ purchased no healthy items and $73.2 \%$ purchased two or more unhealthy items. The proportion of students who purchased healthy items was smaller than $12 \%$ per item. This predominance of unhealthy purchases over healthy ones was unrelated to gender but was attenuated in students who were $17 \mathrm{y}$ and older (i.e., although $85.7 \%$ of all students purchased more unhealthy than healthy items, this was decreased to $73.1 \%$ in the older group, $P<0.05$ ).

Table 3 indicates that three of the most frequently purchased items at school, namely potato chips, candies/chocolate, and French fries, had the highest caloric content per serving $[22,23]$. This reflects their high content of fat and/or added sugar. Based on the serving sizes listed in Table 3, a snack consisting of two frequently purchased items, namely potato chips and a soft drink, supplies $10.8 \mathrm{~g}$ of fat, $2 \mathrm{~g}$ of protein, $35 \mathrm{~g}$ of sugar, and $301 \mathrm{kcal}$ compared with a snack of brown bread and whole milk, which provides $9.5 \mathrm{~g}$ of fat, $13.5 \mathrm{~g}$ of protein, $0 \mathrm{~g}$ of sugar, and $286 \mathrm{kcal}$. Although the first snack provides only $1.2 \mathrm{~g}$ of fiber, the second one provides $4.0 \mathrm{~g}$ and is a much better source of micronutrients.

Students were tested to determine whether they could correctly distinguish between defined healthy and unhealthy foods. With six or nine foods, at least $84 \%$ of students correctly identified which foods were healthy and which were unhealthy (Table 4). However, with regard to cola drinks (Coca-Cola), samoosas, and pies, only $47 \%$ to $61 \%$ indicated that these items were unhealthy. Students' scores on this question were unrelated to whether they purchased healthy or unhealthy food items.

The schools were classified as being of high SES $(n=4)$ or low SES $(n=10)$. Students who attended high SES schools were no more likely to have breakfast before school and were twice as likely to bring food to school $(64.7 \%$ versus $31.0 \%, P<0.001$ ). These students at high SES schools were slightly less likely to purchase food at school (64.4\% versus $71.7 \%$, not significant), but, not surprisingly, they spent twice as much money at school (6.3 versus 3.1 rands, $P<0.001)$. They scored higher marks on the knowledge test of healthy/unhealthy foods $(P<0.01)$ but were no more likely to purchase healthy foods.

\section{Discussion}

Our findings shine some light on the food consumption patterns of adolescent students in schools in Cape Town, South Africa. The aspects of the study dealing with food purchases by students is an area of research that has been much neglected to date.

Table 2

Foods purchased by students

\begin{tabular}{|c|c|c|c|}
\hline $\begin{array}{l}\text { Food } \\
\text { classification }\end{array}$ & Food item & Rationale for classification into healthy/unhealthy & $\begin{array}{l}\text { Proportion }(\%) \text { of } \\
\text { students buying this } \\
\text { food* }^{*}\end{array}$ \\
\hline \multirow[t]{4}{*}{ Healthy } & Fruit & $\begin{array}{l}\text { High in fiber, high nutrient density, no fat or added sugar, low sodium, } \\
\text { low in calories }\end{array}$ & 11.8 \\
\hline & Fruit juice & $\begin{array}{l}\text { High nutrient density, no fat, low sodium (sometimes the juice is } \\
\text { sweetened) }\end{array}$ & 10.7 \\
\hline & Nuts & High in protein, no added sugar, good source of nutrients & 6.5 \\
\hline & Brown bread & High in fiber, high nutrient density, low in fat and added sugar & 4.6 \\
\hline \multirow[t]{9}{*}{ Unhealthy } & Potato chips & High in fat and sodium, high in calories & 46.3 \\
\hline & Candies (sweets), chocolates & $\begin{array}{l}\text { High in saturated fat, high in added sugar, low in fiber, high in } \\
\text { calories, low nutrient density }\end{array}$ & 46.0 \\
\hline & Soft drinks & High in added sugar, low fiber, low nutrient density & 33.2 \\
\hline & French fries & High in fat and sodium, high in calories & 25.6 \\
\hline & Meat pies, sausage rolls & High in saturated fat and sodium, high in calories & 12.2 \\
\hline & Cookies (biscuits), cakes, and similar & $\begin{array}{l}\text { High in saturated fat, high in added sugar, low in fiber, high in } \\
\text { calories, low nutrient density }\end{array}$ & 11.8 \\
\hline & $\begin{array}{l}\text { "Fat cakes" (deep-fried bread dough } \\
\text { shaped in balls) }\end{array}$ & High in fat and sodium, low in fiber, high in calories & 9.5 \\
\hline & Hot dogs (sausage on white roll) & High in saturated fat and sodium, low in fiber, high in calories & 8.2 \\
\hline & White bread & Lower in fiber than brown bread, lower nutrient density & 5.5 \\
\hline
\end{tabular}

* Only those food items purchased by at least $4.6 \%$ of students are listed. 
Table 3

Nutritional value of foods purchased by students (per serving)*

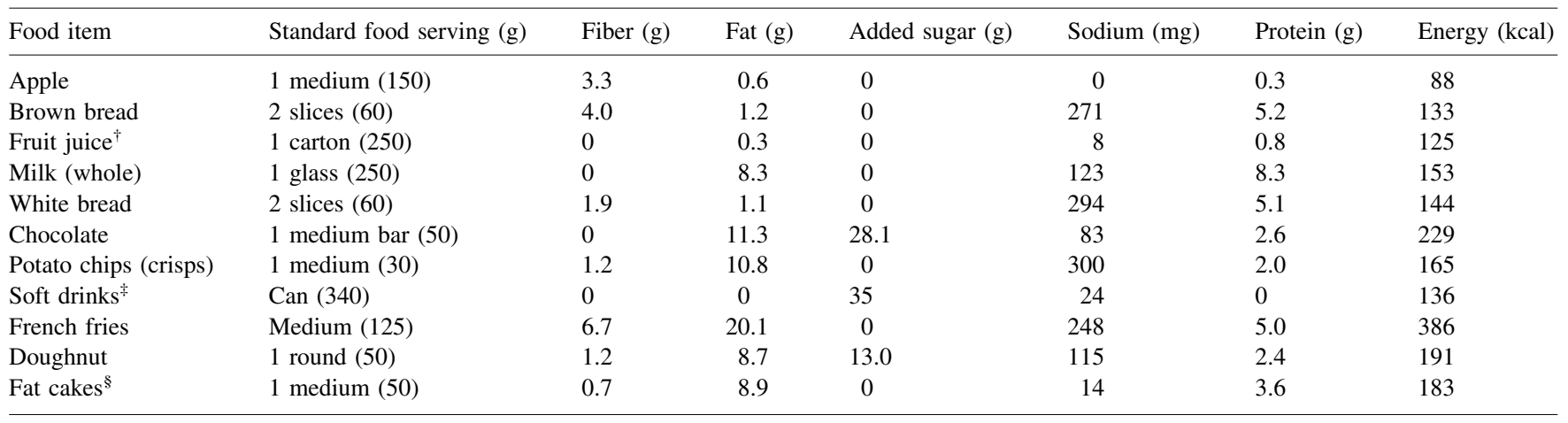

* Based on Langenhoven et al. [22,23].

${ }^{\dagger}$ Peach and orange juice.

* Soft drinks with sugar (not artificially sweetened).

${ }^{\S}$ Balls of bread flour dough deep fried in oil.

The study has strengths and weaknesses. We used a large sample $(n=476)$ and selected students from 14 schools to have a representative sample of the various ethnic groups and SESs of the city. One limitation of the study was that some inconsistencies were found in a few of the answers despite our precautions to prevent this.

The findings show that $22 \%$ of children in this study did not have breakfast before school. Consistent with these results, other data from South Africa have indicated that $15 \%$ to $20 \%$ of children do not have anything to eat or drink before they go to school in the morning [24,25]. Skipping breakfast may have detrimental outcomes on physiologic and scholastic achievements, particularly in disadvantaged children who are undernourished [26]. This is particularly relevant in Cape Town because a survey in the Western Cape, of which Cape Town is a part, indicated that, among 11- to 12-y-old colored and black children in urban areas, $16 \%$ were stunted $(<5$ th percentile, National Center for Health Statistics) [27]. For this reason, one would wish schools to provide healthy foods, particularly for those who have not eaten before school. Another strong motive for the provision of healthy food items is in relation to the high prevalence of overweight among children at schools in

Table 4

Students' ability to distinguish between healthy and unhealthy foods

\begin{tabular}{lll}
\hline Food classification & Food & Correct answer (\%) \\
\hline Healthy & Apples & 98.5 \\
& Brown bread & 95.1 \\
Unhealthy & Tuna sandwich & 85.2 \\
& Potato chips (crisps) & 84.4 \\
& Chocolates & 88.7 \\
& Candies (sweets) & 91.4 \\
& Coca-Cola & 60.8 \\
& Samoosas* & 52.7 \\
& Pies & 47.4
\end{tabular}

* Triangles of pastry with filling and deep fried.

${ }^{\dagger}$ All items having a rich flaky type of pastry and a filling (usually meat).
South Africa. In the National Food Consumption Survey, 9.5\% of 7- to 8-y-old children had a body mass index of at least $25 \mathrm{~kg} / \mathrm{m}^{2}$ [20].

Nearly $80 \%$ of students in the present study ate at school during the recorded time, with the majority purchasing this food at school. Contrary to our expectations, a large percentage of students did not bring healthy items from home. Whether this is due to poor nutritional knowledge or specific preferences of the mothers and students is not known. However, the results from this study show that, overall, children know which foods are healthier choices, even though it did not affect their buying behavior. Similar results were found in a study by Bloom [11] at a private school in Cape Town. Nutritional knowledge scores were found to be high overall, but learners were found to opt for unhealthy food and drink options. Therefore, nutritional knowledge did not correlate with healthy eating practices.

A survey undertaken in rural black children found that foods most commonly brought to school were healthier options: brown bread (54\%), fruit (50\%), and eggs (46\%). However, there was still a substantial number who had white bread (43\%) and fat cakes (40\%) [10]. It is probable that in rural areas children have a more traditional diet with less junk food options. This was found to be the case in young black university students in the same province [28]. Those from rural areas had a lower consumption of sugar and animal products and a higher consumption of legumes.

Most food items purchased at the schools in the present study can be regarded as being unhealthier options. About three-fourths of the food purchased at school came from a store in the school (tuck shop), with the remainder coming from a local vendor. This suggests that, if the nutritional quality of food sold in the school store were improved, there would be a significant improvement in the overall diet. The case for this is strengthened when viewed in light of the large proportion of children who had no breakfast and the large proportion of students who were stunted and/or over- 
weight. A necessary first step should be the education of parents and children with regard to the essentials and importance of a healthy diet.

One strategy aimed at getting children to eat healthier foods at schools is to change the pricing structure of foods sold in school stores. An informative study along these lines was carried out in a high school cafeteria in the United States [29]. The price of fruit, carrots, and salads was halved, resulting in a four-fold increase in sales of fruit, a two-fold increase for carrots, and a slight increase for salads. What this study graphically illustrates is the potential for policy intervention, especially low prices, to redirect food choices toward healthier products.

Another strategy is one aimed at controlling or regulating the advertising of unhealthy foods to children. In 2003 the American Academy of Pediatrics [30] released a policy statement on the prevention of pediatric overweight and obesity:

Advertising and promotion of energy-dense, nutrientpoor food products to children may need to be regulated or curtailed. The increase in carbonated beverage intake has been linked to obesity; therefore, the sale of such beverages should not be promoted at school. Pediatricians are encouraged to work with school administrators and others in the community on ways to decrease the availability of foods and beverages with little nutritional value and to decrease the dependence on vending machines, snack bars, and school stores for school revenue.

In South Africa, this system is currently unregulated with regard to advertising to children.

\section{Recommendations}

It is likely that the most sustainable strategy would be to implement policy interventions such as regulations that restrict what foods can be sold in schools coupled with strategic nutritional education programs at the school level. Recently, the department of health initiated a new strategy for nutritional education that is based on the food-based dietary guidelines as recommended by the World Health Organization in 1999 [31]. The South African guidelines have been officially adopted by the department of health to form part of the Integrated Nutrition Programme [32]. These guidelines are being widely promulgated as part of nutritional intervention programs aimed at developing healthy lifestyles [33].

In conclusion, it is important that national initiatives to improve the diet of South Africans as part of a healthy lifestyle [22] are also reflected by foods offered at school stores. It is therefore recommended that the initiation of food-based dietary guidelines in South Africa by the department of health should also be implemented by the department of education. This means that the food-based dietary guidelines need to be accepted as policy for schools and that only foods that are in accord with these guidelines should be allowed to be sold at schools.

\section{Acknowledgments}

The authors are grateful to Lindsay Guyn, B.Sc., for expert assistance with the statistical analysis.

\section{References}

[1] Andersen LB, Wedderkopp N, Hansen HS, Cooper AR, Froberg K. Biological cardiovascular risk factors cluster in Danish children and adolescents: the European Youth Heart Study. Prev Med 2003;37: 363-7.

[2] Caballero B. Early nutrition and risk of disease in the adult. Public Health Nutr 2001;4:1335-6.

[3] Law M. Dietary fat and adult diseases and the implications for childhood nutrition: an epidemiologic approach. Am J Clin Nutr 2000;72(suppl):1291S-6.

[4] Boreham C, Twisk J, van Mechelen W, Savage M, Strain J, Cram G. Relationships between the development of biological risk factors for coronary heart disease and lifestyle parameters during adolescence: the Northern Ireland Young Hearts Project. Public Health 1999;113: $7-12$.

[5] Munoz KA, Krebs-Smith SM, Ballard-Barbash R, Cleveland LE. Food intakes of US children and adolescents compared with recommendations. Pediatrics 1997;100:323 (erratum Pediatrics 1998;101: 952-3).

[6] Pomerleau J, Lock K, McKee M, Altmann DR. The challenge of measuring global fruit and vegetable intake. J Nutr 2004;134:117580

[7] Barquera S, Rivera JA, Safdie M, Flores M, Campos-Nonato I, Campirano F. Energy and nutrient intake in preschool and school age Mexican children: National Nutrition Survey 1999. Salud Publica Mex 2003;45(suppl 4):S540-50.

[8] Florentino RF, Villavieja GM, Lana RD. Dietary and physical activity patterns of 8- to 10-year-old urban schoolchildren in Manila, Philippines. Food Nutr Bull 2002;23:267-73.

[9] Wildey MB, Pampalone SZ, Pelletier RL, Zive MM, Elder JP, Sallis JF. Fat and sugar levels are high in snacks purchased from student stores in middle schools. J Am Diet Assoc 2000;100:319-22.

[10] Steyn NP, Badenhorst CJ, Nel JH. The meal pattern and snacking habits of schoolchildren in two rural areas of Lebowa. S Afr J Food Sci Nutr 1993;5:5-10.

[11] Bloom D. Adolescent obesity and factors such as nutrition knowledge and practices influencing the development thereof (unpublished thesis). Cape Town: University of Cape Town; 2003.

[12] Kant AK. Reported consumption of low-nutrient density foods by American children and adolescents. Nutritional and health correlates, NHANES III, 1988 to 1994. Arch Pediatr Adolesc Med 2003;57: 789-96.

[13] Bowman SA, Gortmaker SL, Ebbeling CB, Pereira MA, Ludwig DS. Effects of fast-food consumption on energy intake and diet quality among children in a national household survey. Pediatrics 2004;113(1 pt 1):112-8.

[14] Jacobson MF. Liquid candy: how soft drinks harm the health of Americans. In: Wilson T, Temple NJ, editors. Beverages in nutrition and health. Totowa, NJ: Humana Press; 2003;351-67.

[15] Harnack L, Stang J, Story M. Soft drink consumption among US children and adolescents: nutritional consequences. J Am Diet Assoc 1999;99:436-41.

[16] Ebbeling CB, Pawlak DB, Ludwig DS. Childhood obesity: publichealth crisis, common sense cure. Lancet 2003;360:473-82. 
[17] Ludwig DS, Peterson KE, Gortmaker SL. Relation between consumption of sugar-sweetened drinks and childhood obesity: a prospective, observational analysis. Lancet 2001;357:505-8.

[18] Labadarios D, editor. The National Food Consumption Survey (NFCS): children aged 1-9 years, South Africa, 1999. Pretoria: Department of Health; 2000.

[19] National Center for Health Statistics. NCHS growth curves for children. Birth to 18 years. DHEW publication PHS 78-1650. Hyattsville, MD: United States Department of Health, Education and Welfare. Public health Services; 1977.

[20] Steyn NP, Labadarios D, Maunder E, Nel J, Lombard C; Directors of the National Food Consumption Survey. Secondary anthropometric data analysis of the National Food Consumption Survey in South Africa: the double burden. Nutrition 2005;21:4-13.

[21] May J. Experience and perceptions of poverty in South Africa. Durban: Praxis; 1998.

[22] Langenhoven ML, Kruger M, Gouws E, Faber M. Medical Research Council food composition tables. 3rd ed. Parow: Research Institute for Nutritional Diseases, South African Medical Research Council; 1991.

[23] Langenhoven ML, Kruger M, Gouws E, Faber M. Medical Research Council food quantities manual. 3rd ed. Parow: Research Institute for Nutritional Diseases, South African Medical Research Council; 1991.

[24] Walker ARP, Walker BF, Jone J, Ncongwane J. Breakfast habits of adolescents in four South African populations. Am J Clin Nutr 1981; $36: 650-5$.
[25] Wolmarans, P, Jooste P, Oelofse A, Albertse EC, Chalton D. Breakfast patterns of South African primary school children in low socioeconomic areas. S Afr J Food Sci Nutr 1995;7:103-6.

[26] Richter LM, Rose C, Griesel RD. Cognitive and behavioural effects of a school breakfast. S Afr Med J 1997;87:93-100.

[27] Steyn NP. Nutritional status of 11-year-old children in the Western Cape province of South Africa (Ph.D. thesis). Stellenbosch, South Africa: University of Stellenbosch; 1988.

[28] Steyn NP, Senekal M, Brits S, Nel JH. Urban and rural differences in dietary intake, weight status and nutrition knowledge of black female students. Asia Pac J Clin Nutr 2000;9:53-9.

[29] French SA, Story M, Jeffery RW, et al. Pricing strategy to promote fruit and vegetable purchase in high school cafeterias. J Am Diet Assoc 1997;97:1008-10.

[30] Committee on Nutrition. Prevention of pediatric overweight and obesity. Pediatrics 2003;112:424-6.

[31] Joint FAO/WHO Consultation. Preparation and use of the food-based dietary guidelines. WHO technical report series 880 . Geneva: World Health Organization; 1998.

[32] South African health review 2002. Durban: Health Systems Trust; 2003.

[33] Whati LH, Senekal M, Steyn NP, Nel JH, Lombard C. Development of a reliable and valid nutrition knowledge questionnaire for urban South African adolescents. Nutrition 2005;21:76-85. 